\title{
mRNA expression of specific HER ligands and their association with clinical outcome in patients with metastatic breast cancer treated with trastuzumab
}

\author{
VASSILIKI RAPTI $^{1 *}$, EVANGELIA MOIROGIORGOU ${ }^{2 *}$, GEORGIA-ANGELIKI KOLIOU $^{3}$, \\ KYRIAKI PAPADOPOULOU ${ }^{4}$, IOANNIS BINAS ${ }^{5}$, GEORGE PENTHEROUDAKIS ${ }^{6,7}$,
} DIMITRIOS BAFALOUKOS ${ }^{8}$, MATTHEOS BOBOS ${ }^{4}$, KYRIAKOS CHATZOPOULOS $^{4}$, SOFIA CHRISAFI $^{4}$, CHRISTOS CHRISTODOULOU ${ }^{5}$, IRENE NICOLAOU ${ }^{9}$, MARIA SOTIROPOULOU ${ }^{10}$, CHRISTINA MAGKOU $^{11}$, ANGELOS KOUTRAS $^{12}$, PAVLOS PAPAKOSTAS ${ }^{13}$, ATHANASIOS KOTSAKIS ${ }^{14}$, EVANGELIA RAZIS ${ }^{15}$, AMANDA PSYRRI ${ }^{16}$, DIMITRIOS TRYFONOPOULOS ${ }^{1}$, DIMITRIOS PECTASIDES ${ }^{17}$, ELENI RES ${ }^{18}$, ATHANASIOS ALEXOPOULOS ${ }^{2}$, VASSILIKI KOTOULA ${ }^{4,19}$ and GEORGE FOUNTZILAS F $^{4,20,21}$

${ }^{1}$ Second Department of Internal Medicine, Agios Savvas Cancer Hospital, 11522 Athens; ${ }^{2}$ Oncology Department, Hygeia Hospital, 15123 Athens; ${ }^{3}$ Section of Biostatistics, Hellenic Cooperative Oncology Group, 11526 Athens;

${ }^{4}$ Laboratory of Molecular Oncology, Hellenic Foundation for Cancer Research/Aristotle University of Thessaloniki,

54006 Thessaloniki; ${ }^{5}$ Second Department of Medical Oncology, Metropolitan Hospital, 18547 Piraeus;

${ }^{6}$ Department of Medical Oncology, Medical School, University of Ioannina; ${ }^{7}$ Society for Study of

Clonal Heterogeneity of Neoplasia (EMEKEN), 45500 Ioannina; ${ }^{8}$ First Department of Medical Oncology,

Metropolitan Hospital, 18547 Piraeus; ${ }^{9}$ Department of Histopathology, Agii Anargiri Cancer Hospital, 14564 Athens;

${ }^{10}$ Department of Pathology, Alexandra Hospital, 11528 Athens; ${ }^{11}$ Pathology Department, Evangelismos Hospital, 10676 Athens; ${ }^{12}$ Division of Oncology, Department of Medicine, University Hospital, University of Patras Medical School, 26504 Patras; ${ }^{13}$ Oncology Unit, Hippokration Hospital, 11527 Athens; ${ }^{14}$ Department of Medical Oncology, University Hospital of Heraklion School of Medicine, University of Crete, 71500 Crete; ${ }^{15}$ Third Department of Medical Oncology, Hygeia Hospital,

15123 Athens; ${ }^{16}$ Section of Medical Oncology, Department of Internal Medicine, Attikon University Hospital,

Faculty of Medicine, National and Kapodistrian University of Athens School of Medicine, 12462 Athens; ${ }^{17}$ Oncology Section, Second Department of Internal Medicine, Hippokration Hospital, 11527 Athens; ${ }^{18}$ Third Department of Medical Oncology,

Agii Anargiri Cancer Hospital, Kifissia 14564 Athens; ${ }^{19}$ Department of Pathology, Aristotle University of Thessaloniki,

School of Health Sciences, Faculty of Medicine, 54006 Thessaloniki; ${ }^{20}$ Aristotle University of Thessaloniki, 54006 Thessaloniki, Greece; ${ }^{21}$ Department of Medical Oncology, German Oncology Center, 4108 Limassol, Cyprus

Received March 26, 2021; Accepted September 22, 2021

DOI: $10.3892 / 01.2021 .13141$

Correspondence to: Dr Vassiliki Rapti, Second Department of Internal Medicine, Agios Savvas Cancer Hospital, 171 Alexandras Avenue, 11522 Athens, Greece

E-mail: v.rapti@yahoo.gr; hecogoff@otenet.gr

${ }^{*}$ Contributed equally

Abbreviations: ER, oestrogen receptors; FISH, fluorescence in situ hybridization; IHC, immunohistochemistry; MBC, metastatic breast cancer; PgR, progesterone receptors; R-MBC, relapsed metastatic breast cancer; RARA, retinoic acid receptor $\alpha$; THRA, thyroid hormone receptor $\alpha$; TTP, time to progression

Key words: metastatic breast cancer, trastuzumab, biomarkers, HER2, HER ligands
Abstract. Prognostic and predictive biomarkers are being studied for the diagnosis and treatment of breast cancer. The present study retrospectively assessed the mRNA expression of HER family receptor ligands and of other potential prognostic biomarkers and their association with time to progression (TTP), survival and clinicopathological characteristics in patients with metastatic breast cancer (MBC) treated with trastuzumab. A total of 145 tumour tissue samples were analysed. mRNA expression analysis of the transcripts of interest was performed and the association of these markers with selected clinicopathological parameters was examined. HER2 status was centrally re-evaluated. Only $67.6 \%$ of patients were truly HER2-positive according to the central HER2 re-evaluation. Heparin binding epidermal growth factor (EGF)-like growth factor, transforming growth factor $\beta 1$ (TGFB1) and thyroid hormone receptor $\alpha$ (THRA) mRNA expression was higher in HER2-positive patients $(\mathrm{P}=0.026$, $\mathrm{P}<0.001$ and $\mathrm{P}<0.001)$. Insulin-like growth factor binding 
protein 4 was correlated with retinoic acid receptor $\alpha$, TGFB1 and THRA (rho $=0.45$, rho $=0.60$ and rho $=0.45$ ). In HER2-positive patients, high neuregulin 1 and high betacellulin were unfavourable factors for TTP [hazard ratio $(\mathrm{HR})=1.78$, $\mathrm{P}=0.040$ and $\mathrm{HR}=2.00, \mathrm{P}=0.043$, respectively]. In patients with de novo $\mathrm{MBC}$, high $\mathrm{EGF}$ expression was associated with a non-significant prolongation of TTP $(\mathrm{HR}=0.52, \mathrm{P}=0.080)$ and significantly longer survival $(\mathrm{HR}=0.40, \mathrm{P}=0.020)$. The present study examined clinical and biological implications of specific genes and it was concluded that their expression has an impact on the outcome of trastuzumab-treated patients with MBC.

\section{Introduction}

Breast cancer is a disease characterised by molecular heterogeneity $(1,2)$. Gene expression profiling has identified molecular subtypes of breast cancer with differences in prognosis and therapeutic options. In particular, the HER2-enriched subtype is characterised by upregulation of the HER2 gene (3), while the HER2 gene is amplified in $15-20 \%$ of all breast carcinomas (4).

The HER2/neu protein is a component of a four-member family of closely related growth factor receptors, including EGFR or HER1 (ERBB1), HER2 (ERBB2), HER3 (ERBB3) and HER4 (ERBB4). HER receptors exist as monodimers, and they can form homodimers or heterodimers when they bind to a ligand. Numerous ligands are associated with HER1, HER3 and HER4, while HER2 is characterised as an 'orphan' receptor, since there is no known ligand that can promote homodimers of HER2. In terms of the HER ligands, epidermal growth factor (EGF), transforming growth factor $\alpha$, the heparin binding EGF-like growth factor (HBEGF), betacellulin (BTC), amphiregulin (AREG) and epiregulin (EREG) bind to the HER1 receptor (5). Neuregulin 1 (NRG1) and neuregulin 2 bind to HER3, while HBEGF, BTC, EREG and neuregulins 1, 2, 3 and 4 bind to HER4 $(6,7)$.

The importance of HER2 as a prognostic or predictive marker in invasive breast cancer is well recognised and, therefore, HER2 status should be determined in all cases of invasive (early stage or recurrent) breast cancer $(8,9)$. HER2 testing includes the evaluation of HER2 protein upregulation assessed by immunohistochemistry (IHC) and HER2 gene amplification assessed by in situ hybridisation, fluorescence in situ hybridisation (FISH), chromogenic in situ hybridisation, silver-enhanced in situ hybridisation or quantitative PCR (10). Although mRNA expression profiling has been used to classify breast tumours into molecular subtypes, assessment of oestrogen receptors (ER)/progesterone receptors (PgR)/HER2 status via IHC is currently the standard in clinical practice for the selection of patients that are more likely to respond to hormone or anti-HER2 treatments, according to international guidelines (11-13).

Previous work has demonstrated that ERBB/HER ligands, including AREG, BTC, EREG, EGF, HBEGF, NRG1 and transforming growth factor $\alpha$ (TGFA), are co-expressed at the mRNA level in breast cancer in various combinations alongside their receptors, whereas associations have also been established among the mRNA levels of the aforementioned ligands and the four HER receptors $(14,15)$. Furthermore, the
mRNA expression patterns of EGF, AREG, TGFA and HBEGF have been linked to clinicopathological parameters, including tumour size and histoprognostic grading (14). However, in the case of EGF, an association with improved prognosis has also been observed for overall survival and relapse-free survival, at least in univariate analyses (14). Specific ERBB/HER ligands, have been linked to treatment response with anti-HER2 therapeutic agents, including trastuzumab, as shown by preclinical or clinical studies (16-18).

Although most HER2-positive patients derive benefit from trastuzumab and other approved anti-HER 2 targeted therapies, resistance will eventually develop and cause disease progression (19). Furthermore, there is a subset of HER2-positive patients that will not respond to trastuzumab due to primary resistance (18). Therefore, it is crucial to identify biomarkers that will allow for the categorisation of patients most likely to either respond to or develop primary and secondary resistance to trastuzumab.

Apart from the HER ligands, the mRNA levels of other molecules, including insulin-like growth factor binding protein 4 (IGFBP4), a member of the family of proteins binding to insulin-like growth factors, transforming growth factor $\beta 1$ (TGFB1), a TGF $\beta$ signalling component, the thyroid hormone receptor $\alpha$ (THRA), and the retinoic acid receptor $\alpha$ (RARA), have been studied in breast cancer for their prognostic significance (20-25). The present study retrospectively examined the mRNA expression of several HER ligands and other potential prognostic biomarkers of interest, including IGFBP4, TGFB1, THRA and RARA, in patients with metastatic breast cancer (MBC) who were treated with trastuzumab. Their relationship with other tumour and pathological characteristics, as well as ER/PgR/HER2 status, assessed centrally by IHC, was evaluated and their prognostic role in terms of progression and survival in this subset of patients was explored.

\section{Materials and methods}

Patients and tissue processing. The present study was conducted on a previously reported group of patients (26) that was enriched with additional cases to achieve a total study population of 145 cases (all female). The eligibility criteria were as follows: i) Treatment with trastuzumab for histologically confirmed MBC; ii) adequate clinical data on patient history, demographics, tumour characteristics, treatment details (i.e., drug dosages, schedule of administration and serious toxicities) and clinical outcome; and iii) adequate tumour tissue available for biological marker evaluation.

Formalin-fixed paraffin-embedded tumour tissue samples were retrospectively collected from patients treated with trastuzumab-based regimens in the metastatic setting, as previously described in detail (26-28). All tumours were characterised by local pathologists as HER2-positive based on American Society of Clinical Oncology/College of American Pathologists (ASCO/CAP) criteria current at that time (29). Consequently, all patients received trastuzumab as part of their treatment. All tumour samples were centrally re-evaluated by IHC for oestrogen receptors (ER), progesterone receptors (PgR), HER2 and the expression of the proliferation marker Ki67. Additionally, HER2 amplification status was assessed using the FISH method, as later described. 
The translational research protocol was approved by the Bioethics Committee of the Aristotle University of Thessaloniki School of Medicine (Protocol \#4283; January 14, 2008; Thessaloniki, Greece) under the general title 'Investigation of major mechanisms of resistance to treatment with trastuzumab in patients with metastatic breast cancer'. All patients included in the study in 2005 and later provided written informed consent for the provision of biological material for future research studies before receiving any treatment. A waiver of consent was obtained from the Bioethics Committee for patients included in the study before 2005 .

Tissue microarrays (TMAs). Representative haematoxylin-eosin-stained $2-\mu \mathrm{m}$ sections from the tissue blocks were reviewed by a pathologist. A total of 17 TMA blocks were constructed from the 145 eligible cases using a manual tissue microarrayer (Beecher Instruments), as previously described (26). For the construction of the TMA blocks, two core samples $(1.5 \mathrm{~mm}$ in diameter) were obtained from representative regions of each tumour in the donor blocks. All IHC and FISH markers were assessed on the TMA sections. The cases not represented, which had damaged or inadequate cores on the TMA sections, were re-cut from the original blocks if still available. These sections were used for protein and gene analyses as previously described $(26-28,30)$. Further method details are provided in Data S1.

Immunohistochemistry (IHC)-tumor infiltrating lymphocytes (TILs). Serial 2.5- $\mu$ m-thick TMA sections or whole tissue sections were stained for ER (clone 6F11; cat. no. NCL-L-ER-6F11; Leica Microsystems, Ltd.), PgR (clone 1A6; cat. no. NCL-L-PGR; Leica Microsystems, Ltd.), HER2 (polyclonal Ab; cat. no. A0485; Dako; Agilent Technologies, Inc.), Ki67 (clone MIB-1; cat. no. M7240; Dako; Agilent Technologies, Inc.), phosphorylated mTOR at serine 2448 (p-mTOR; clone 49F9; cat. no. 2976; Cell Signaling Technology, Inc.; dilution, 1:30; $20 \mathrm{~min}$ ) and stPTEN (clone 6H2.1; cat. no. M3627; Dako; Cell Signaling Technology, Inc.; dilution, 1:200; $30 \mathrm{~min}$ ), using the Bond Max $^{\mathrm{TM}}$ autostainer (Leica Microsystems, Ltd.) as previously described in detail (31) (Table SI). All sections were stained in one run for each antibody and were evaluated by pathologists experienced in breast cancer and blinded to the patient's clinical and survival data. Positive controls were used for all antibodies from known positive breast cancer cases, while negative controls were obtained by omitting the primary antibody as previously described (26-28,30).

All IHC stains were evaluated according to the formerly outlined interpretation (32). Stromal TIL density was assessed on whole H\&E sections according to the guidelines from the International TILs Working Group (33) and was analysed as a continuous variable. HER2 protein expression was scored according to the 2007 ASCO/CAP guidelines (29) (scores between 0 and $3+$ ). A positive for HER2 protein expression (IHC 3+) was defined as uniform intense membrane staining of $>30 \%$ of invasive tumour cells. Further method details are provided in Data $\mathrm{S} 1$.

Fluorescence in situ hybridisation (FISH). TMA sections or whole tissue sections (5- $\mu$ m-thick) were used for FISH analysis using the ZytoLight ${ }^{\circledR}$ SPEC HER2/TOP2A/CEN17 triple colour probe kit for HER2 (code Z-2093; ZytoVision GmbH). FISH was performed according to the manufacturer's protocol with minor modifications (pepsin solution was applied to the specimens and incubated for $11-12 \mathrm{~min}$ at $37^{\circ} \mathrm{C}$ in a humidified chamber) in all cases (i.e., not only the HER2 IHC $2+$ cases). Digital images were constructed using software specifically developed for cytogenetics (XCyto-Gen, ver 1.2.11; Alphelys) and evaluated as previously described (26,31). For the assessment of HER2 status, the 2007 ASCO/CAP guidelines (29) were used with the addition of the $\geq 6$-HER2-copies criterion (34), as patients had locally received trastuzumab according to this classification. HER2 status was considered positive if HER2 was amplified by FISH and/or a HER2 score of 3+ was obtained by IHC. Representative IHC and FISH images from invasive breast carcinoma cases are presented in Fig. 1. Further method details are provided in Data S1.

Dual nucleic acid extraction and mRNA expression analysis. Simultaneous isolation of DNA and RNA from whole or macrodissected $10-\mu \mathrm{m}$ paraffin sections, the latter in cases with $<50 \%$ tumour cell content, was performed for the 145 examined tumours with iron oxide beads coated with a nanolayer of silica using the VERSANT Tissue Preparation Reagents kit (Siemens Healthcare Diagnostics) as previously described (35). The nucleic acid extract of each sample was divided into two aliquots. DNase I was then added to one aliquot in order to remove DNA and ensure the presence of pure RNA for downstream mRNA analyses. cDNA synthesis was performed with random primers and SuperScript III Reverse Transcriptase (catalogue number 48190011 and 18080044; Invitrogen; Thermo Fisher Scientific, Inc.) according to the manufacturer's instructions. cDNAs were assessed in duplicate with quantitative PCR using an ABI7900HT system under default thermal cycling conditions as follows: $50^{\circ} \mathrm{C}$ for $2 \mathrm{~min}$, $95^{\circ} \mathrm{C}$ for $10 \mathrm{~min}$, followed by 45 cycles at $95^{\circ} \mathrm{C}$ for $15 \mathrm{sec}$ and $60^{\circ} \mathrm{C}$ for $1 \mathrm{~min}$, respectively.

mRNA expression analysis was performed with pre-made exon-spanning TaqMan-MGB assays (Applied Biosystems; Thermo Fisher Scientific, Inc.) targeting the following gene transcripts (data in parentheses refer to assay ID; exon boundary; amplicon length): AREG Hs00950669_m1; 3-4; 66 bp), BTC Hs01101204_m1; 4-5, 5-6 ; 139 bp), EGF Hs01099999_m1; 19-20, 20-21: 70 bp), EREG ID Hs00914313_m1; 3-4; 65 bp), HBEGF Hs00181813_m1; 3-4; 78 bp), IGFBP4 Hs00181767_ m1; 1-2: 91 bp), NRG1 Hs00247620_m1; 2-3: 93 bp), RARA Hs00940446_m1; 4-5, 5-6, 6-7: 68 bp), TGFA Hs00608187_ m1; 4-5: 70 bp), TGFB1 Hs00171257_m1; 1-2: 63 bp), THRA Hs00268470_m1; 4-5: 89 bp) (Table I). A TaqMan-MGB expression assay targeting the glucuronidase $\beta$ (GUSB) gene (Hs99999908_m1; 9-10, 10-11, 11-12; 81 bp) was used as the endogenous reference for relative quantification. The commercially available TaqMan Control Total RNA (cat. no. 4307281; Applied Biosystems; Thermo Fisher Scientific, Inc.) was applied as a positive control for interrun evaluation of the PCR assay efficiency, together with no-template controls. To obtain linear relative quantification (RQ) values, relative expression was assessed as $40-\Delta \mathrm{Cq}$, whereby $\Delta \mathrm{Cq}$ was calculated as (average target $\mathrm{Cq}$ ) - (average GUSB Cq) from all eligible measurements, as previously described (35). Only samples 

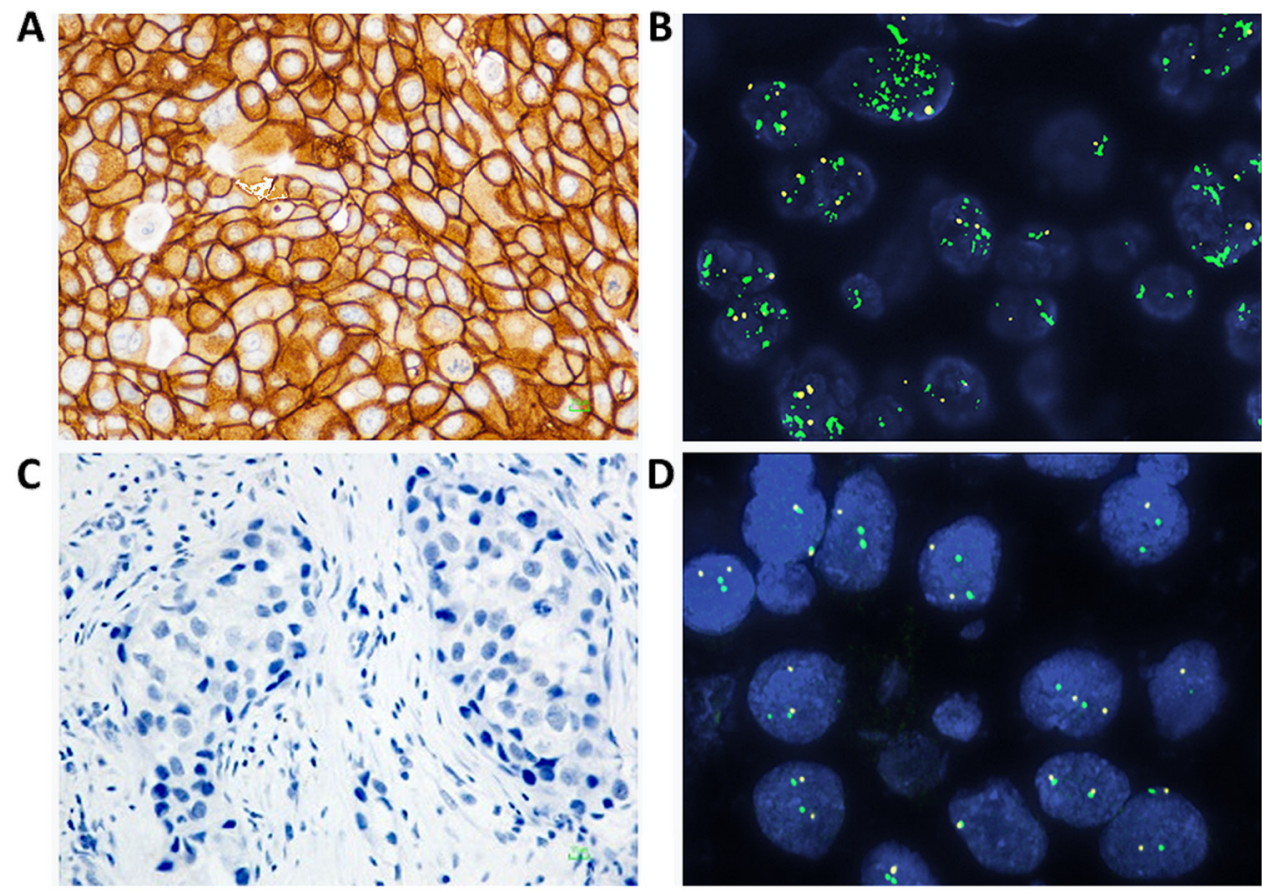

Figure 1. Representative IHC and FISH images from IBC cases. (A and B) In the first two panels an IBC case with (A) HER2 upregulation and (B) gene amplification is shown. (C and D) IBC HER2-negative case stained by (C) IHC and (D) FISH. HER2/TOP2A/CEP17 triple-colour probe: HER2 gene probe, green; CEP17 probe, yellow. The TOP2A gene probe (red) was excluded in the images using the XCytoGen software for cytogenetics. Magnification, x1,000. CEP17, centromeric region of chromosome 17; FISH, fluorescence in situ hybridization; IBC, invasive breast carcinoma; IHC, immunohistochemistry; TOP2A, DNA topoisomerase II $\alpha$.

with average GUSB Cq values $<36$ and a $\triangle \mathrm{RQ}$ value for each duplicate sample pair (intrarun variation) of $<1$ were considered eligible for further analysis in the present study.

Statistical analysis. Frequencies with the corresponding percentages and medians with range were used to summarize categorical and continuous variables, respectively. Comparisons of categorical data were performed using the $\chi^{2}$ or Fisher's exact test (if more appropriate), while the non-parametric Wilcoxon rank-sum test was applied for the comparison of categorical with continuous variables. Associations of the markers of interest were assessed using Spearman's correlations.

The median value of the mRNA expression of the examined markers was used as the optimal cut-off to classify tumours into high- and low-expression groups and assess their prognostic significance and the associations with several clinicopathological characteristics (including age, menopausal status, histological grade, TIL density, PTEN expression and bone metastasis). Additionally, we evaluated the upper and lower quartiles of the mRNA distribution as potential thresholds. Time to progression (TTP) was defined as the time interval between the initiation of trastuzumab-based treatment for advanced disease (with or without parallel administration of chemotherapy or hormonal therapy) and the first documented disease progression. Non-progressors were censored at the date of last follow-up. Survival was also estimated from the initiation of trastuzumab-based therapy until death (from any cause) or last follow-up. Time-to-event distributions were estimated with the Kaplan-Meier method and comparisons of groups were performed with the log-rank test. Cox proportional hazard regression models (univariate and multivariate) were applied to estimate the effect of the examined markers on TTP and survival.

The TTP and survival analyses were conducted separately in the subgroup of HER2-positive and HER2-negative patients (as defined by HER 2 central assessment), while the interactions with the ER/PgR status among patients with HER2-positive tumours and with the disease presentation status in the entire study population were also assessed for all examined markers with respect to TTP and survival to detect whether the effect of the marker expression on patients' outcome varied between the subgroups defined by ER/PgR (positive vs. negative) and disease presentation status [relapsed MBC (R-MBC) vs. de novo $\mathrm{MBC}]$.

Model choice was performed in multivariate analyses using the following variables in the first step: Menopausal status, performance status, mTOR protein expression, PTEN protein expression and each one of the markers that showed significance in univariate analysis. The final model was selected using backward selection criteria with $\mathrm{P}<0.10$. All tests were two-sided and significance was set at $5 \%$. The SAS software (version 9.3; SAS Institute, Inc.) was used for the statistical analyses.

\section{Results}

Patient characteristics and trastuzumab exposure. A total of 145 patients with at least one measurement in the markers of interest, including HER family receptor ligands and other potential prognostic biomarkers, were included in the present study. Among them, 109 (75.2\%) had available mRNA data 
Table I. Premade TaqMan-MGB assays for mRNA expression analysis.

\begin{tabular}{|c|c|c|c|c|c|}
\hline Gene symbol & Assay ID, Hs & Size, bp & Exons & Gene name & Genbank ref \\
\hline AREG & Hs00950669_m1 & 66 & $3-4$ & Amphiregulin & NM_001657.3 \\
\hline BTC & Hs01101204_m1 & 139 & $4-5,5-6$ & Betacellulin & $\begin{array}{l}\text { NM_001316963.1, } \\
\text { NM_001729.3 }\end{array}$ \\
\hline EGF & Hs01099999_m1 & 70 & $\begin{array}{l}19-20,19-20, \\
20-21\end{array}$ & $\begin{array}{l}\text { Epidermal growth } \\
\text { factor }\end{array}$ & $\begin{array}{l}\text { NM_001178130.2, } \\
\text { NM_001178131.2, } \\
\text { NM_001963.5 }\end{array}$ \\
\hline EREG & Hs00914313_m1 & 65 & $3-4$ & Epiregulin & NM_001432.2 \\
\hline HBEGF & Hs00181813_m1 & 78 & $3-4$ & $\begin{array}{l}\text { Heparin binding EGF } \\
\text { like growth factor }\end{array}$ & NM_001945.2 \\
\hline IGFBP4 & Hs00181767_m1 & 91 & $1-2$ & $\begin{array}{l}\text { Insulin like growth factor } \\
\text { binding protein } 4\end{array}$ & NM_001552.2 \\
\hline NRG1 & Hs00247620_m1 & 93 & $2-3$ & Neuregulin 1 & $\begin{array}{l}\text { NM_001159995.2, } \\
\text { NM_001159999.2, } \\
\text { NM_001160001.2, } \\
\text { NM_001160002.1, } \\
\text { NM_001160004.2, } \\
\text { NM_001160005.1, } \\
\text { NM_001160007.1, } \\
\text { NM_001160008.1, } \\
\text { NM_013956.4, } \\
\text { NM_013957.4, } \\
\text { NM_013958.3, } \\
\text { NM_013960.4, } \\
\text { NM_013962.2, } \\
\text { NM_013964.4, } \\
\text { NM_004495.3 }\end{array}$ \\
\hline RARA & Hs00940446_m1 & 68 & $\begin{array}{c}4-5,5-6,6-7 \\
6-7\end{array}$ & $\begin{array}{l}\text { Retinoic acid } \\
\text { receptor } \alpha\end{array}$ & $\begin{array}{l}\text { NM_001145302.2, } \\
\text { NM_001024809.3, } \\
\text { NM_001145301.2, } \\
\text { NM_000964.3 }\end{array}$ \\
\hline TGFA & Hs00608187_m1 & 70 & $4-5$ & $\begin{array}{l}\text { Transforming growth } \\
\text { factor } \alpha\end{array}$ & $\begin{array}{l}\text { NM_001099691.1, } \\
\text { NM_001308158.1, } \\
\text { NM_001308159.1 }\end{array}$ \\
\hline TGFB1 & Hs00171257_m1 & 63 & $1-2$ & $\begin{array}{l}\text { Transforming growth } \\
\text { factor } \beta 1\end{array}$ & NM_000660.5 \\
\hline THRA & Hs00268470_m1 & 89 & $4-5$ & $\begin{array}{l}\text { Thyroid hormone } \\
\text { receptor } \alpha\end{array}$ & $\begin{array}{l}\text { NM_001190918.1, } \\
\text { NM_001190919.1, } \\
\text { NM_003250.5, } \\
\text { NM_199334.3 }\end{array}$ \\
\hline GUSB & Hs99999908_m1 & 81 & $\begin{array}{l}9-10,9-10 \\
10-11,11-12\end{array}$ & Glucuronidase $\beta$ & $\begin{array}{l}\text { NM_001284290.1, } \\
\text { NM_001293105.1, } \\
\text { NM_001293104.1, } \\
\text { NM_000181.3 }\end{array}$ \\
\hline
\end{tabular}

for all 11 markers. Although all patients were found to be HER2-positive when assessed at the local institutions and, therefore, were treated with trastuzumab, only 98 patients $(67.6 \%)$ were classified as HER2-positive by the central re-evaluation of HER2 status. Therefore, 47 patients (32.4\%) were treated with trastuzumab despite being HER2-negative (Fig. 2). 


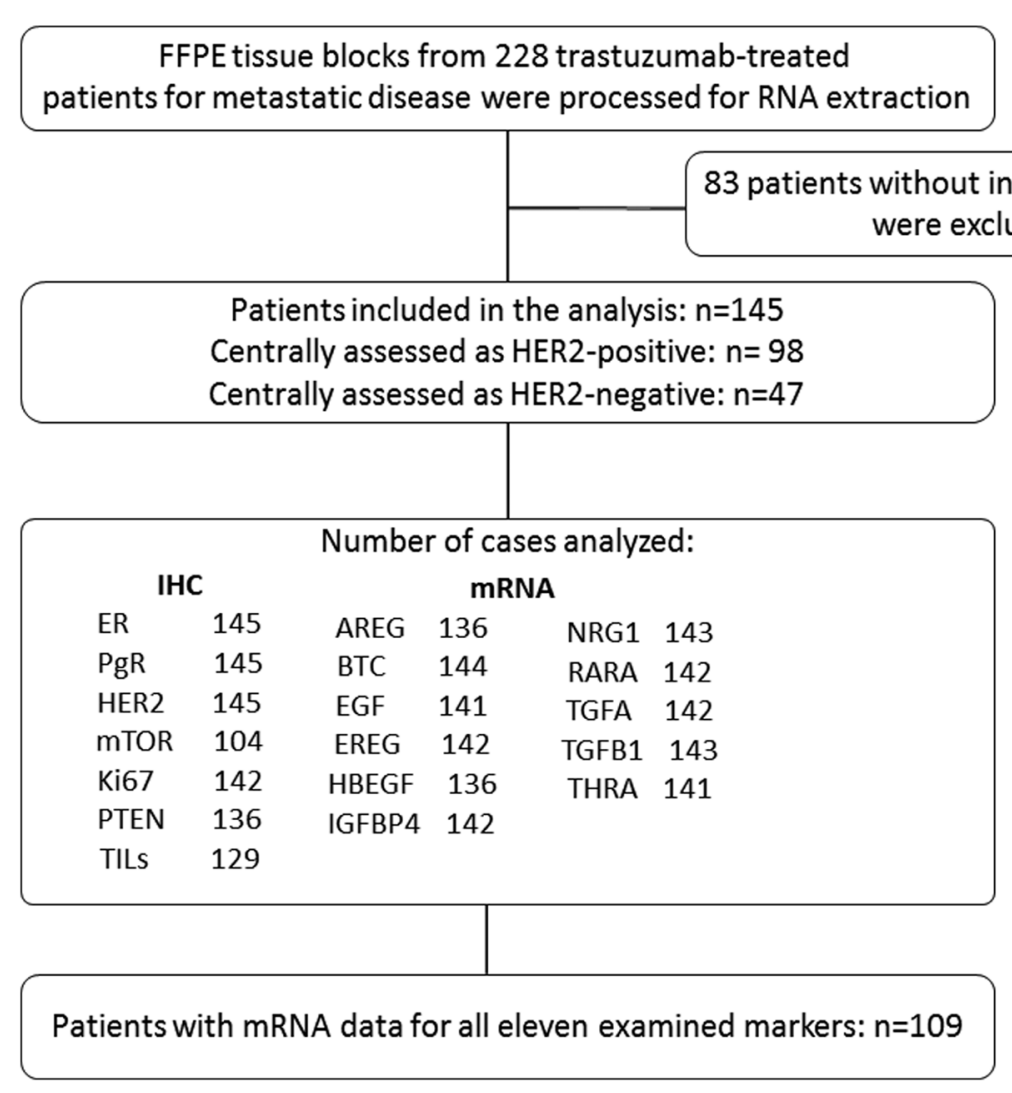

Figure 2. Reporting recommendations for tumour marker prognostic studies (REMARK) diagram. AREG, amphiregulin; BTC, betacellulin; EGF, epidermal growth factor; ER, oestrogen receptors; EREG, epiregulin; FFPE, formalin-fixed paraffin-embedded; HBEGF, heparin Binding EGF like growth factor; IGFBP4, insulin-like growth factor binding protein 4; IHC, immunohistochemistry; NRG1, neuregulin 1; PgR, progesterone receptors; RARA, retinoic acid receptor $\alpha$; TGFA, transforming growth factor $\alpha$; TGFB1, transforming growth factor $\beta 1$; THRA, thyroid hormone receptor $\alpha$; TILs, tumour-infiltrating lymphocytes.

Selected patient and tumour characteristics for the entire study population and by HER 2 status, as defined by the central assessment, are shown in Table II. A total of 69 patients (47.6\%) had stage IV disease at the time of diagnosis (de novo MBC), while $52.4 \%$ had R-MBC. Most women were of postmenopausal status at the time of trastuzumab initiation (72.4\%), while the majority of the patients with R-MBC had received adjuvant chemotherapy $(85.5 \%)$. The median age at the initiation of trastuzumab-based therapy was 56 years (range, 29-86 years).

In total, 132 patients $(91.0 \%)$ received trastuzumab as a first-line treatment, while 9 patients $(6.2 \%)$ were treated with trastuzumab as a second-line treatment. The remaining patients received trastuzumab as third- to seventh-line therapy. In 130 patients (89.7\%), trastuzumab was administered with chemotherapy, whereas 13 patients received hormonal therapy at the time of trastuzumab initiation, and 2 patients received trastuzumab as monotherapy. In addition, 6 patients $(4.1 \%)$ had been previously treated with a trastuzumab regimen in the adjuvant and/or neoadjuvant setting.

Marker distribution by HER 2 status. The distribution of the markers of interest based on the normalised expression of mRNA-encoding genes is presented in Fig. S1. The distribution of all examined markers by HER2 status (based on central assessment) is presented in Table SII, while Table SIII presents the distribution of markers by ER/PgR status among
HER2-positive patients. Table SIV shows the distribution of markers by disease presentation status for the entire study population. HER2-positive patients presented with higher HBEGF, TGFB1 and THRA mRNA expression compared with patients with HER2-negative tumours $(\mathrm{P}=0.026, \mathrm{P}<0.001$ and $\mathrm{P}<0.001$, respectively; Table SII), while IGFBP4 mRNA expression was higher in HER2-positive patients with positive ER/PgR status compared with HER2-positive patients with $\mathrm{ER} / \mathrm{PgR}$-negative tumours ( $\mathrm{P}=0.004$; Table SII). No significant differences were observed in the distribution of the markers of interest between patients with de novo $\mathrm{MBC}$ and $\mathrm{R}-\mathrm{MBC}$ (Table SIV).

Correlations among HER family receptor ligands. IGFBP4 was positively strongly correlated with RARA (rho $=0.45$; $\mathrm{P}<0.001)$, TGFB1 (rho $=0.60 ; \mathrm{P}<0.001)$ and THRA (rho $=0.45$; $\mathrm{P}<0.001)$. In addition, RARA was strongly and positively correlated with THRA (rho $=0.52 ; \mathrm{P}<0.001)$. A strong correlation was also detected between TGFB1 and THRA (rho $=0.51$; $\mathrm{P}<0.001)$ and between $\mathrm{BTC}$ and EREG (rho=0.47; $\mathrm{P}<0.001$; Fig. 3).

Association of HER family ligand receptors with clinicopathological characteristics. Patients carrying tumours with high AREG mRNA expression (using the median value as a cut-off point) were of younger age at the time of trastuzumab initiation and were more frequently premenopausal compared 
Table II. Selected patient and tumour characteristics in groups of patients divided by HER2 status.

\begin{tabular}{|c|c|c|c|}
\hline \multirow[b]{2}{*}{ Characteristics } & \multicolumn{3}{|c|}{ HER2 status (by central assessment) } \\
\hline & Total $(n=145)$ & Negative $(n=47)$ & Positive $(n=98)$ \\
\hline Median age, years (range) ${ }^{\mathrm{a}}$ & $56(29-86)$ & $58(33-76)$ & $54(29-86)$ \\
\hline De novo $\mathrm{MBC}, \mathrm{n}(\%)$ & $69(47.6)$ & $18(38.3)$ & $51(52.0)$ \\
\hline $\mathrm{R}-\mathrm{MBC}, \mathrm{n}(\%)$ & $76(52.4)$ & $29(61.7)$ & $47(48.0)$ \\
\hline History of adjuvant CT, $\mathrm{n}(\%)^{\mathrm{b}}$ & $65(85.5)$ & $26(89.7)$ & $39(83.0)$ \\
\hline Anthracycline-based adjuvant CT, n (\%) & $52(68.4)$ & $20(69.0)$ & $32(68.1)$ \\
\hline Taxane-containing CT, $\mathrm{n}(\%)^{\mathrm{b}}$ & $33(43.4)$ & $9(31.0)$ & $24(51.1)$ \\
\hline CMF-based CT, n $(\%)^{\mathrm{b}}$ & $32(42.1)$ & $15(51.7)$ & $17(36.2)$ \\
\hline History of adjuvant $\mathrm{HT}, \mathrm{n}(\%)^{\mathrm{b}}$ & $46(60.5)$ & $20(69.0)$ & $26(55.3)$ \\
\hline History of adjuvant RT, n (\%) & $43(56.6)$ & $16(55.2)$ & $27(57.4)$ \\
\hline \multicolumn{4}{|l|}{ Histological grade, $\mathrm{n}(\%)$} \\
\hline I-II & $50(34.5)$ & $19(40.4)$ & $31(31.6)$ \\
\hline III & $88(60.7)$ & $25(53.2)$ & $63(64.3)$ \\
\hline Unknown & $7(4.8)$ & $3(6.4)$ & $4(4.1)$ \\
\hline \multicolumn{4}{|l|}{ Menopausal status, $\mathrm{n}(\%)^{\mathrm{a}}$} \\
\hline Premenopausal & $39(26.9)$ & $13(27.7)$ & $26(26.5)$ \\
\hline Postmenopausal & $105(72.4)$ & $34(72.3)$ & $71(72.4)$ \\
\hline Unknown & $1(0.7)$ & $0(0.0)$ & $1(1.0)$ \\
\hline \multicolumn{4}{|l|}{$\mathrm{N}$ of trastuzumab lines, $\mathrm{n}(\%)$} \\
\hline 1 & $59(40.7)$ & $22(46.8)$ & $37(37.8)$ \\
\hline 2 & $32(22.1)$ & $10(21.3)$ & $22(22.4)$ \\
\hline 3 & $24(16.6)$ & $6(12.8)$ & $18(18.4)$ \\
\hline$\geq 4$ & $30(20.7)$ & $9(19.1)$ & $21(21.4)$ \\
\hline \multicolumn{4}{|l|}{ Performance status, $\mathrm{n}(\%)^{\mathrm{a}}$} \\
\hline $0-1$ & $137(94.5)$ & $41(87.2)$ & $96(98.0)$ \\
\hline $2-3$ & $5(3.4)$ & $4(8.5)$ & $1(1.0)$ \\
\hline Unknown & $3(2.1)$ & $2(4.3)$ & $1(1.0)$ \\
\hline \multicolumn{4}{|l|}{ Subtype classification, n (\%) } \\
\hline Luminal A & $7(4.8)$ & $7(14.9)$ & $0(0.0)$ \\
\hline Luminal B & $30(20.7)$ & $30(63.8)$ & $0(0.0)$ \\
\hline Luminal-HER2 & $56(38.6)$ & $0(0.0)$ & $56(57.1)$ \\
\hline HER2-enriched & $42(29.0)$ & $0(0.0)$ & $42(42.9)$ \\
\hline TNBC & $8(5.5)$ & $8(17.0)$ & $0(0.0)$ \\
\hline Unknown & $2(1.4)$ & $2(4.3)$ & $0(0.0)$ \\
\hline \multicolumn{4}{|l|}{$\mathrm{N}$ of metastatic sites, $\mathrm{n}(\%)^{\mathrm{a}}$} \\
\hline $1-3$ & $126(86.9)$ & $37(78.7)$ & $89(90.8)$ \\
\hline$\geq 4$ & $16(11.0)$ & $8(17.0)$ & $8(8.2)$ \\
\hline Unknown & $3(2.1)$ & $2(4.3)$ & $1(1.0)$ \\
\hline \multicolumn{4}{|l|}{ Sites of metastasis, $\mathrm{n}(\%)^{\mathrm{a}}$} \\
\hline Locoregional & $44(30.3)$ & $17(36.2)$ & $27(27.6)$ \\
\hline Distant & $127(87.6)$ & $41(87.2)$ & $86(87.8)$ \\
\hline Only locoregional & $8(5.5)$ & $3(6.4)$ & $5(5.1)$ \\
\hline Only distant & $90(62.1)$ & $27(27.6)$ & $63(64.3)$ \\
\hline Bones & $60(41.4)$ & $21(44.7)$ & $39(39.8)$ \\
\hline Nodes & $28(19.3)$ & $10(21.3)$ & $18(18.4)$ \\
\hline Visceral metastases & $98(67.6)$ & $29(61.7)$ & $69(70.4)$ \\
\hline
\end{tabular}

${ }^{\mathrm{a} A t}$ initiation of trastuzumab treatment; bOnly for patients with relapsed metastatic breast cancer. CMF, cyclophosphamide/methotrexate/5 fluorouracil; CT, chemotherapy; HT, hormonal therapy; MBC, metastatic breast cancer; R-MBC, relapsed metastatic breast cancer; RT, radiotherapy; TNBC, triple-negative breast cancer. 


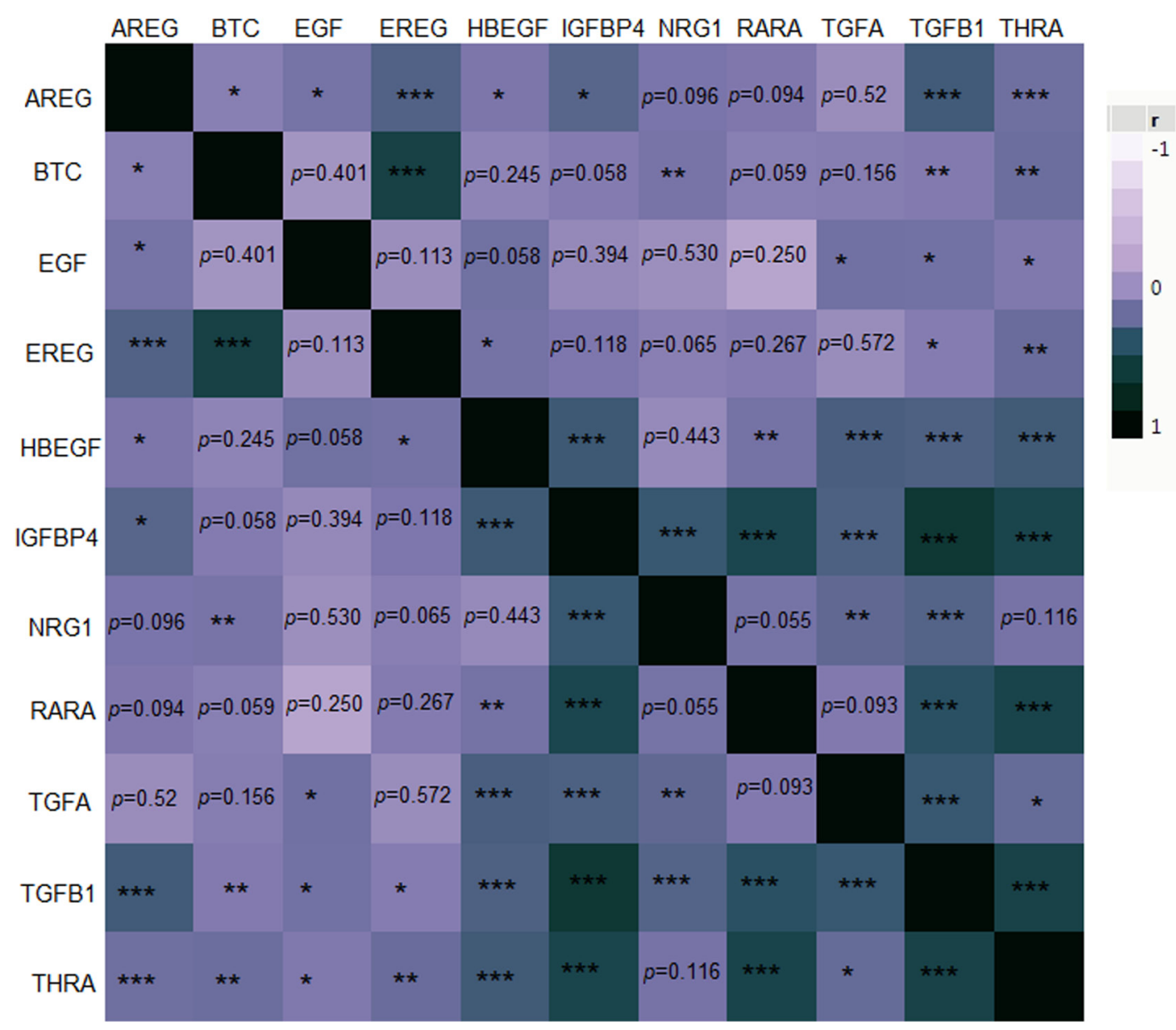

Figure 3. Heatmap matrix plot showing Spearman's correlation coefficients (rho) among the examined markers in the entire cohort. The value of $r$ ranges between -1 (light purple) and 1 (dark green) as explained in the legend corresponding to negative or positive correlations between the markers. "P<0.050, ${ }^{* *} \mathrm{P}<0.010$ and ${ }^{* * *} \mathrm{P}<0.001$, respectively. Non-significant P-values are stated explicitly. AREG, amphiregulin; BTC, betacellulin; EGF, epidermal growth factor; EREG, epiregulin; HBEGF, heparin Binding EGF like growth factor; IGFBP4, insulin-like growth factor binding protein 4; NRG1, neuregulin 1; r, Spearman's correlation coefficient; RARA, retinoic acid receptor $\alpha$; TGFA, transforming growth factor $\alpha$; TGFB1, transforming growth factor $\beta 1$; THRA, thyroid hormone receptor $\alpha$.

with those with low AREG mRNA expression ( $\mathrm{P}=0.002$ and $\mathrm{P}=0.002$, respectively). Younger age was also associated with high NRG1 mRNA expression $(\mathrm{P}=0.030)$, while lower histological grade was associated with high IGFBP4 mRNA expression $(\mathrm{P}=0.008)$. Patients with high mRNA expression levels of RARA, as compared with those with low expression (using the median value as a cut-off point), more frequently exhibited bone metastasis $(\mathrm{P}=0.012)$. Higher TIL density was observed in tumours with high TGFA mRNA expression (using the median value as a cut-off point), while PTEN loss was associated with low mRNA expression levels of TGFA and THRA, using the median values as cut-off points $(\mathrm{P}=0.043$, $\mathrm{P}=0.045$ and $\mathrm{P}=0.003$, respectively; Table $\mathrm{SV}$ ).

Association of markers with patient outcome. The median follow-up time for HER2-positive and HER2-negative patients was 120.3 and 114.2 months, respectively. During this time, 108 patients (74.5\%) died (72 HER2-positive, 73.5\%; 36 HER2-negative, 76.6\%), while 113 (77.9\%) experienced disease progression (76 HER2-positive, 77.6\%; 37 HER2-negative, 78.7\%). The median TTP was 15.1 months (95\% CI, 12.6-19.6) and 11.6 months (95\% CI, 7.1-17.6) for HER2-positive and HER2-negative patients, respectively.
The median survival was 48.5 months (95\% CI, 39.2-59.8) for HER2-positive patients and 38.1 months (95\% CI, 25.8-49.1) for HER2-negative patients, while no significant differences were observed between HER2-positive and HER2-negative patients in terms of TTP or survival $(\mathrm{P}=0.33$ and $\mathrm{P}=0.26$, respectively).

High NRG1 mRNA expression (using the median value as a cut-off) and high BTC mRNA expression (using the upper quartile as a cut-off) was associated with an increased risk of progression in the HER2-positive population (Table III; Fig. 4). In the HER2-negative population, high EREG mRNA expression (using the median value as a cut-off) was univariately associated with a decreased risk of progression (hazard ratio $=0.45 ; 95 \% \mathrm{CI}, 0.23-0.90 ; \mathrm{P}=0.025)$. However, this was not retained upon the adjustment for clinicopathological parameters $(\mathrm{P}=0.12)$.

A significant interaction was observed between the disease presentation status and EGF mRNA expression (using the median value as a cut-off) for TTP (interaction $\mathrm{P}=0.037$ ). High EGF mRNA expression was associated with a decreased risk of progression among patients with de novo MBC (Table III), while the hazard ratio was of the opposite direction in the subgroup of R-MBC women, even though significance was 
Table III. Hazard ratios and 95\% confidence intervals estimated by univariate and multivariate Cox regression analyses for TTP and survival.

\begin{tabular}{|c|c|c|c|c|c|c|}
\hline \multirow[b]{2}{*}{ Parameter, endpoint } & \multicolumn{3}{|c|}{ Univariate } & \multicolumn{3}{|c|}{ Multivariate $^{\mathrm{a}}$} \\
\hline & $\mathrm{HR}$ & $95 \% \mathrm{CI}$ & P-value & $\mathrm{HR}$ & $95 \%$ CI & P-value \\
\hline \multicolumn{7}{|l|}{ TTP } \\
\hline \multicolumn{7}{|l|}{ HER2-positive patientsb } \\
\hline $\begin{array}{l}\text { NRG1 mRNA expression (median as } \\
\text { high vs. low) }\end{array}$ & 1.63 & $1.03-2.57$ & 0.035 & 1.78 & $1.03-3.09$ & 0.040 \\
\hline $\begin{array}{l}\text { BTC mRNA expression (upper quartile as } \\
\text { cut-off value; high vs. low) }\end{array}$ & 1.90 & $1.12-3.24$ & 0.018 & 2.00 & $1.02-3.93$ & 0.043 \\
\hline \multicolumn{7}{|l|}{ Patients with de novo $\mathrm{MBC}$} \\
\hline $\begin{array}{l}\text { EGF mRNA expression (median value as } \\
\text { cut-off; high vs. low) }\end{array}$ & 0.55 & $0.32-0.94$ & 0.029 & 0.52 & $0.25-1.08$ & 0.080 \\
\hline \multicolumn{7}{|l|}{ Survival } \\
\hline $\begin{array}{l}\text { Patients with de novo MBC } \\
\text { EGF mRNA expression (lower quartile as } \\
\text { cut-off; high vs. low) }\end{array}$ & 0.46 & $0.24-0.87$ & 0.017 & 0.40 & $0.19-0.87$ & 0.020 \\
\hline
\end{tabular}

${ }^{\mathrm{a} R e s u l t s ~ o f ~ b a c k w a r d s ~ s e l e c t i o n ~ m o d e l s . ~}{ }^{\mathrm{b}}$ According to HER2 central re-evaluation. BTC, betacellulin; CI, confidence interval; EGF, epidermal growth factor; HR, hazard ratio; MBC, metastatic breast cancer; NRG1, neuregulin 1; TTP, time to progression.
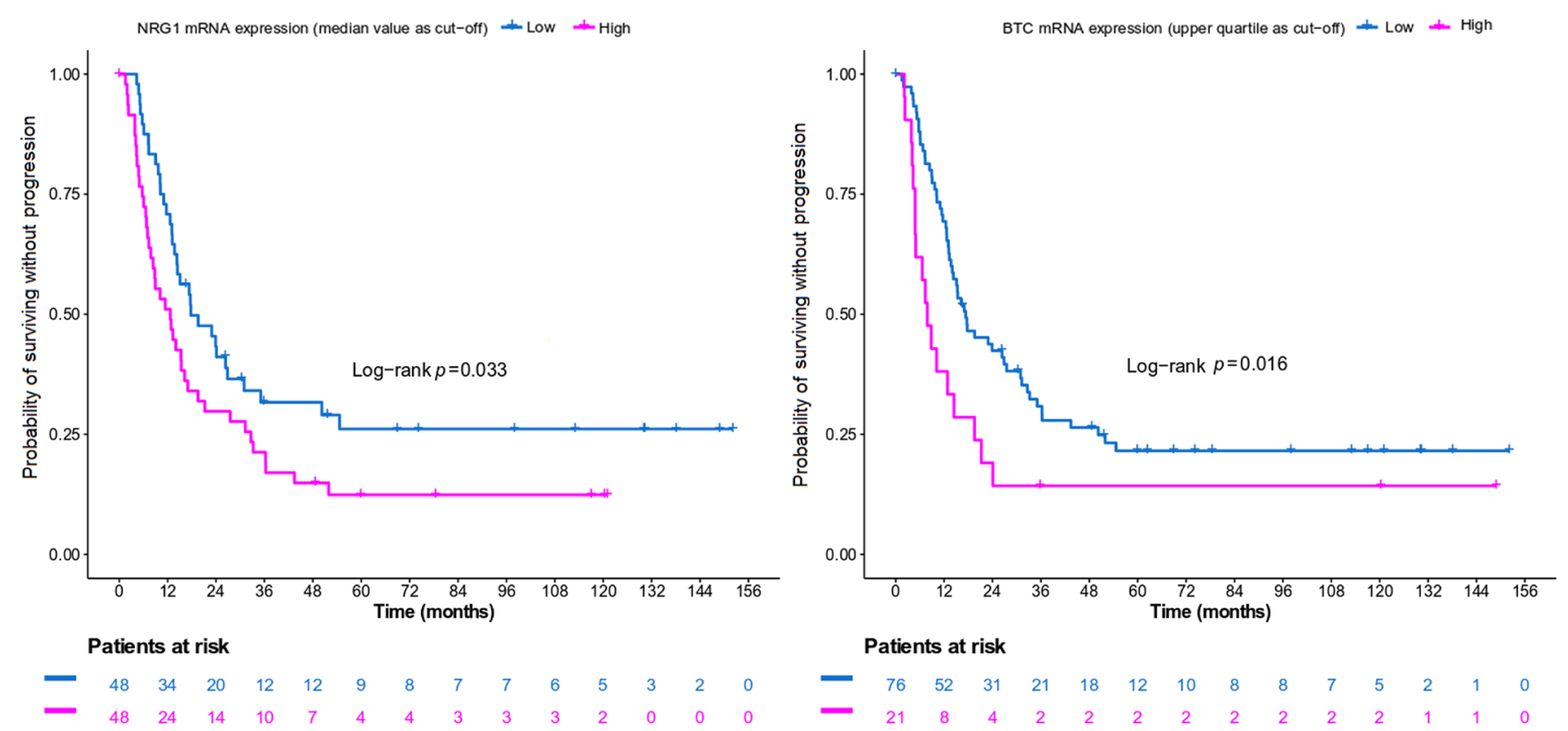

Figure 4. Kaplan-Meier curves with respect to TTP based on NRG1 and BTC mRNA expression in HER2-positive patients. BTC, betacellulin; NRG1, neuregulin 1; TTP, time to progression.

not reached $(\mathrm{P}=0.43)$. After adjustment for clinicopathological parameters, a non-significant trend towards improved TTP was observed for patients with de novo MBC carrying tumours with high EGF mRNA expression compared with those with low expression.

In terms of survival, a significant interaction was identified between disease presentation status and EGF expression (using the lower quartile as a cut-off; interaction $\mathrm{P}=0.045$ ). In the subgroup of patients with de novo $\mathrm{MBC}$, high EGF expression was associated with a decreased risk of death (Table III). No significance was reached among patients with $\mathrm{R}-\mathrm{MBC}(\mathrm{P}=0.82)$.

\section{Discussion}

The present study examined the expression of the ERBB family receptor (ERBB1, ERBB3 and ERBB4) ligands and of other putative prognostic biomarkers, including THRA, RARA, 
TGFB1 and IGFBP4, and their association with clinicopathological parameters and clinical outcomes in patients treated with trastuzumab-based therapy for MBC. Tissue samples from the primary tumours were examined for all patients in the study. In addition, a cohort of metastatic HER2-negative patients treated with trastuzumab was assessed. In the present study, 47 patients $(32.4 \%)$ were found to be HER2-positive in the local institution and HER2 negative in the central re-assessment and were treated with anti-HER2 therapy.

In the literature, discordance between local and central laboratories in HER2 results, using either IHC or FISH, has been reported (9). Repeat testing is recommended if results appear contradictory to other histopathologic findings (8). In an N9831 study, the concordance for central HercepTest and central FISH assays was 92\%, while a National Surgical Adjuvant Breast and Bowel Project (NSABP-B) prospective adjuvant trastuzumab study revealed an $18 \%$ discordance rate between local and central laboratories in HER2 testing (36-38). A number of factors may contribute to this discordance, such as tumour heterogeneity, borderline HER2-positive samples, difficulty in evaluating tumours with chromosome 17 polysomy, methodologic factors, such as antibody sensitivity, antigen retrieval, tissue processing, lack of concordance between IHC and FISH, and lack of experience of pathologists, especially in the early years of trastuzumab use, and low-volume testing laboratories $(36,39,40)$. In the present study, additional factors, such as the limited experience of local pathologists with the IHC HER2 assessment and the adoption of a 4-point scale of HER2 status for the administration of trastuzumab, especially during the early years of its registration, may have contributed to the observed discordance.

This discordance highlights the main advantage of the central assessment of HER2 testing. Testing must be performed in central laboratories, which are able to show high concordance with a validated HER2 test on a large set of specimens. Expression of HER2 is a predictive factor of response to anti-HER2 therapies and therefore, accurate testing of HER2 is of great importance. According to the NSABP B47 study, HER2-low tumours do not derive any benefit from the addition of 1 year of trastuzumab to standard chemotherapy (41). In the present study, no significant difference was found between HER2-positive and HER2-negative patients in terms of TTP or survival, a finding that can be explained by the improvement of prognosis of HER2-positive tumours due to trastuzumab. It is clear that the use of trastuzumab improved the outcomes of the HER2-positive breast tumours and transformed those tumours into less aggressive ones (42). The question that remains, however, is whether treatment with trastuzumab equalised the prognosis between HER2-positive and HER2-negative MBC.

The amplification or upregulation of the HER2 oncogene identifies patients for whom HER2-directed therapy is appropriate. There is a subset of HER2-positive patients that will not respond to trastuzumab or other approved anti-HER2 targeted therapies due to primary or secondary resistance (19). A number of mechanisms of resistance to trastuzumab have been described, and one of these is increased signalling from other ERBB family receptors $(18,43)$. The initial signal is generated by the extracellular ligands of the ERBB family receptors, which leads to the dimerisation of two HER family receptors and transphosphorylation of their intracellular regions, with subsequent activation of a number of downstream signalling pathways (44).

The present study examined the mRNA expression of the specific HER family receptor ligands and their association with patient outcomes. It was demonstrated that NRG1 had a negative prognostic value in the trastuzumab-treated HER2-positive MBC population, as high NRG1 mRNA expression was associated with an increased risk for disease progression in both univariate and multivariate analyses. In breast cancer, NRG1 is known as a ligand for the HER3 receptor, which has no intrinsic tyrosine kinase activity. When activated by NRG1 binding, the HER3 receptor forms a heterodimer with other HER family receptors and mediates downstream signalling pathways, leading to multiple effects, including growth, proliferation, decreased apoptosis, cellular migration and angiogenesis (45).

In the literature, NRG expression is associated with poor outcomes and high-risk features of breast carcinoma, as this gene promotes metastatic dissemination of breast cancer cells (46). Similarly, a previous study has revealed that NRG1/HER3 activation is one of the key factors inducing primary resistance to trastuzumab in HER2-overexpressing breast cancer cells and that a HER3 antibody may reverse primary trastuzumab resistance by inhibiting the activation of NRG1-dependent HER3 (47). The present results are consistent with the literature and suggest upregulation of NRG1 as a potential mechanism of resistance to trastuzumab that leads to an increased risk of disease progression. This finding is important because it could lead to the development of novel drugs to overcome the resistance to trastuzumab and other anti-HER2 treatments.

Another study demonstrated that upregulation of the NRG1-HER3 axis is a mechanism of resistance in HER2-positive breast cancer cell lines and xenografts treated with anti-HER2 therapy, and that multitargeted antibody mixtures, such as Pan-HER, inhibit the growth of drug-sensitive and drug-resistant HER2+ cancers (48). In addition, in our cohort of HER2-positive patients, BTC mRNA expression was found to have a negative prognostic value for TTP. This was a novel finding regarding the effect of BTC on the clinical outcome of patients with HER2-positive disease that should be taken into consideration and interpreted with caution until it can be further validated in larger cohorts.

In HER2-negative patients, high EREG mRNA expression was univariately associated with a decreased risk of progression, but this was not retained in the multivariate analysis. At the same time, a significant interaction was detected between EGF mRNA expression and disease presentation status in all patients with respect to TTP. More specifically, the univariate analysis revealed that EGF mRNA might represent a positive prognostic factor for TTP in de novo metastatic patients. In the multivariate analysis, a trend associated with a lower risk of progression was observed for high EGF mRNA, while longer survival was confirmed for patients with tumours with high EGF mRNA expression in the same subgroup of patients.

EGF expression in breast cancer is associated with poor outcomes and aggressive phenotypes, such as low hormone receptor levels, high proliferation index and HER2 upregulation (49). In a review article by Ross and Fletcher (50), EGFR expression was associated with a higher risk of relapse in 
patients with breast cancer. It has been hypothesized that high EGF mRNA is a potential mechanism of trastuzumab resistance, as the growth inhibition by trastuzumab in HER2-positive breast cancer cell lines is blocked by increased levels of the HER family ligands, such as heregulin and EGF $(43,51)$. Furthermore, there is evidence that EGF stimulates the synthesis of its own receptor (EGFR) in a human breast cancer cell line (52). Additionally, in the North Central Cancer Treatment Group N9831 (Alliance) trial, patients with high expression levels of EGFR derived a decreased benefit from adjuvant trastuzumab administered concurrently with chemotherapy (53).

Based on all the aforementioned results, one can reasonably assume that high EGF mRNA and subsequent activation of EGFR-mediated signalling pathways act as a potential mechanism of resistance to trastuzumab and, therefore, should be related to a higher risk of progression and death in trastuzumab-treated HER2-positive patients. The results of the present study, however, are not consistent with the literature, since in the present study, high EGF mRNA expression was associated with a decreased risk of progression among patients with de novo MBC. One explanation could be that de novo (vs. recurrent) metastatic patients were not pre-treated with trastuzumab and had not developed resistance to trastuzumab, although this assumption cannot explain the positive prognostic value of high EGF in this subgroup of patients. In addition, only a small subset $(4.1 \%)$ of patients in the present study received trastuzumab in the adjuvant or neoadjuvant setting.

Another explanation could be based on the 'EGFR paradox' in primary vs. MBC (54). According to this paradox, there are fundamental changes in EGFR signalling in metastases compared with primary breast tumours, such as EGF-induced apoptosis and EGF-induced growth arrest. This means that EGFR acts as a tumour driver in primary breast cancer and as a tumour suppressor in metastatic disease (55). In the present study, in recurrent metastatic patients, tissue from the primary tumour and not from the metastases was examined, which could explain the positive prognostic value of high EGF mRNA only in the de novo metastatic patients.

The present study is an exploratory study consisting mainly of hypotheses generated with limited samples. The results should be further validated in a larger cohort. Among the strengths of the present study are the long follow-up of patients and the central assessment of HER2 status, which precludes any false-positive cases. Furthermore, this is the first study to collectively evaluate ligands of all three HER2 receptors in patients with MBC.

In conclusion, the present results provided evidence suggesting that there may be an association between HER family ligand expression and clinical outcome in patients with HER2-positive and HER2-negative MBC who received trastuzumab-based therapy. High NGR1 mRNA expression was a negative prognostic factor for progression among patients with HER2-positive MBC, while high EGF mRNA expression was a positive prognostic factor for progression only in patients with de novo $\mathrm{MBC}$. In addition, it was observed that the HER2-negative trastuzumab-treated subgroup of patients had similar TTP and survival compared with the HER2-positive group.
$\mathrm{MBC}$ is a heterogeneous disease with poor prognosis. Although survival in HER2-positive breast cancer has been improved due to anti-HER2 directed therapies, further studies are required to improve the prognostic outcomes of patients with this disease.

\section{Acknowledgements}

The authors would like to thank Ms. Emily Daskalaki (Department of Pathology, Aristotle University of Thessaloniki, School of Health Sciences, Faculty of Medicine, Thessaloniki, Greece) for providing technical assistance with molecular methods, including mRNA expression analysis by qPCR, Ms. Eneida Jaupaj for tissue sample collection and Ms. Maria Moschoni for data coordination (both Hellenic Cooperative Oncology Group, Data Office, Athens, Greece).

\section{Funding}

The study was supported by a research grant from F.Hoffmann-La Roche and by an internal HeCOG research grant (HE TRANS_BR).

\section{Availability of data and materials}

The datasets generated and/or analyzed during the current study are available at https://files.hecog.gr/RQ_mRNA_data. xls.

\section{Authors' contributions}

VR, VK and GF were responsible for the conceptualization of the study. Formal analysis was performed by GAK. Experiments and data collection were completed by KP, MB, $\mathrm{KC}, \mathrm{SC}$ and VK. VR, EM, IB, GP, DB, CC, IN, MS, CM, AKou, PP, AKot, ERa, AP, DT, DP, ERe, AA and GF were involved in patient provision, data acquisition and analysis, and critical revision of the manuscript. EM, VK and GF supervised the study. VR, EM, GAK, KP, SC, VK and GF were responsible for writing the original draft. KP and GF confirm the authenticity of all the raw data. All authors have read and approved the final manuscript.

\section{Ethics approval and consent to participate}

The translational research protocol was approved by the Bioethics Committee of the Aristotle University of Thessaloniki School of Medicine (Protocol \#4283; January 14, 2008; Thessaloniki, Greece) under the general title 'Investigation of major mechanisms of resistance to treatment with trastuzumab in patients with metastatic breast cancer'. All patients included in the study from 2005 onwards provided written informed consent for the provision of biological material for future research studies before receiving any treatment. A waiver of consent was obtained from the Bioethics Committee for patients included in the study before 2005 .

\section{Patient consent for publication}

Not applicable. 


\section{Competing interests}

EM Advisory boards: Roche; GP advisory role: Roche; research funding: Roche. CC Advisory role: Roche; honoraria: Roche; advisory role: Roche. PP Advisory role: Roche; honoraria: Roche. AK Consulting or advisory role: Roche. ER Travel: Roche. AP Consultation Fees: Roche; honoraria: Roche. DP Advisory role: Roche; honoraria: Roche. GF Advisory Board: Roche.

\section{References}

1. Hu Z, Fan C, Oh DS, Marron JS, He X, Qaqish BF, Livasy C, Carey LA, Reynolds E, Dressler L, et al: The molecular portraits of breast tumors are conserved across microarray platforms. BMC Genomics 7: 96, 2006.

2. O'Brien KM, Cole SR, Tse CK, Perou CM, Carey LA, Foulkes WD, Dressler LG, Geradts J and Millikan RC: Intrinsic breast tumor subtypes, race, and long-term survival in the Carolina Breast Cancer Study. Clin Cancer Res 16: 6100-6110, 2010.

3. Rilke F, Colnaghi MI, Cascinelli N, Andreola S, Baldini MT, Bufalino R, Della Porta G, Ménard S, Pierotti MA and Testori A: Prognostic significance of HER-2/neu expression in breast cancer and its relationship to other prognostic factors. Int J Cancer 49 : 44-49, 1991.

4. Cronin KA, Harlan LC, Dodd KW, Abrams JS and Ballard-Barbash R: Population-based estimate of the prevalence of HER-2 positive breast cancer tumors for early stage patients in the US. Cancer Invest 28: 963-968, 2010.

5. Alroy I and Yarden Y: The ErbB signaling network in embryogenesis and oncogenesis: Signal diversification through combinatorial ligand-receptor interactions. FEBS Lett 410: 83-86, 1997.

6. Rubin I and Yarden Y: The basic biology of HER2. Ann Oncol 12 (Suppl 1): S3-S8, 2001.

7. Ferreira PMP and Pessoa C: Molecular biology of human epidermal receptors, signaling pathways and targeted therapy against cancers: new evidences and old challenges. Braz J Pharm Sci 53: 1-17, 2017.

8. Harris L, Fritsche H, Mennel R, Norton L, Ravdin P, Taube S, Somerfield MR, Hayes DF and Bast RC Jr; American Society of Clinical Oncology: American Society of Clinical Oncology 2007 update of recommendations for the use of tumor markers in breast cancer. J Clin Oncol 25: 5287-5312, 2007.

9. Wolff AC, Hammond ME, Hicks DG, Dowsett M, McShane LM, Allison KH, Allred DC, Bartlett JM, Bilous M, Fitzgibbons P, et al; American Society of Clinical Oncology; College of American Pathologists: Recommendations for human epidermal growth factor receptor 2 testing in breast cancer: American Society of Clinical Oncology/College of American Pathologists clinical practice guideline update. J Clin Oncol 31: 3997-4013, 2013.

10. Noone AM, Cronin KA, Altekruse SF, Howlader N, Lewis DR, Petkov VI and Penberthy L: Cancer Incidence and Survival Trends by Subtype Using Data from the Surveillance Epidemiology and End Results Program, 1992-2013. Cancer Epidemiol Biomarkers Prev 26: 632-641, 2017.

11. Wolff AC, Hammond MEH, Allison KH, Harvey BE, Mangu PB, Bartlett JMS, Bilous M, Ellis IO, Fitzgibbons P, Hanna W, et al: Human Epidermal Growth Factor Receptor 2 Testing in Breast Cancer: American Society of Clinical Oncology/College of American Pathologists Clinical Practice Guideline Focused Update. J Clin Oncol 36: 2105-2122, 2018.

12. Allison KH,HammondMEH,Dowsett M,McKerninSE,CareyLA, Fitzgibbons PL, Hayes DF, Lakhani SR, Chavez-MacGregor M, Perlmutter J, et al: Estrogen and Progesterone Receptor Testing in Breast Cancer: American Society of Clinical Oncology/College of American Pathologists Guideline Update. Arch Pathol Lab Med 144: 545-563, 2020.

13. Filipits M, Rudas M, Singer CF, Fitzal F, Bago-Horvath Z, Greil R, Balic M, Lax SF, Halper S, Hulla W, et al: ESR1, PGR, ERBB2, and MKi67 mRNA expression in postmenopausal women with hormone receptor-positive early breast cancer: Results from ABCSG Trial 6. ESMO Open 6: 100228, 2021.

14. Révillion F, Lhotellier V, Hornez L, Bonneterre J and Peyrat JP: ErbB/HER ligands in human breast cancer, and relationships with their receptors, the bio-pathological features and prognosis. Ann Oncol 19: 73-80, 2008.
15. Gajria D and Chandarlapaty S: HER2-amplified breast cancer: Mechanisms of trastuzumab resistance and novel targeted therapies. Expert Rev Anticancer Ther 11: 263-275, 2011.

16. Smith BL, Chin D, Maltzman W, Crosby K, Hortobagyi GN and Bacus SS: The efficacy of Herceptin therapies is influenced by the expression of other erbB receptors, their ligands and the activation of downstream signalling proteins. Br J Cancer 91: 1190-1194, 2004

17. Motoyama AB, Hynes NE and Lane HA: The efficacy of ErbB receptor-targeted anticancer therapeutics is influenced by the availability of epidermal growth factor-related peptides. Cancer Res 62: 3151-3158, 2002.

18. Vernieri C, Milano M, Brambilla M, Mennitto A, Maggi C, Cona MS, Prisciandaro M, Fabbroni C, Celio L, Mariani G, et al: Resistance mechanisms to anti-HER2 therapies in HER2-positive breast cancer: Current knowledge, new research directions and therapeutic perspectives. Crit Rev Oncol Hematol 139: 53-66, 2019.

19. Wong ALA and Lee SC: Mechanisms of Resistance to Trastuzumab and Novel Therapeutic Strategies in HER2-Positive Breast Cancer. Int J Breast Cancer 2012: 415170, 2012.

20. Wang J, Luo XX, Tang YL, Xu JX and Zeng ZG: The prognostic values of insulin-like growth factor binding protein in breast cancer. Medicine (Baltimore) 98: e15561, 2019.

21. Chen C, Zhao KN, Masci PP, Lakhani SR, Antonsson A, Simpson PT and Vitetta L: TGF $\beta$ isoforms and receptors mRNA expression in breast tumours: Prognostic value and clinical implications. BMC Cancer 15: 1010, 2015.

22. Heublein S, Mayr D, Meindl A, Angele M, Gallwas J, Jeschke U and Ditsch N: Thyroid Hormone Receptors Predict Prognosis in BRCA1 Associated Breast Cancer in Opposing Ways. PLoS One 10: $\mathrm{e}$ 0127072, 2015.

23. Ditsch N, Toth B, Himsl I, Lenhard M, Ochsenkühn R, Friese K, Mayr D and Jeschke U: Thyroid hormone receptor (TR)alpha and TRbeta expression in breast cancer. Histol Histopathol 28: 227-237, 2013.

24. Hua S, Kittler R and White KP: Genomic antagonism between retinoic acid and estrogen signaling in breast cancer. Cell 137: 1259-1271, 2009

25. Ross-Innes CS, Stark R, Holmes KA, Schmidt D, Spyrou C, Russell R, Massie CE, Vowler SL, Eldridge M and Carroll JS: Cooperative interaction between retinoic acid receptor-alpha and estrogen receptor in breast cancer. Genes Dev 24: 171-182, 2010.

26. Razis E, Bobos M, Kotoula V, Eleftheraki AG, Kalofonos HP, Pavlakis K, Papakostas P, Aravantinos G, Rigakos G, Efstratiou I, et al: Evaluation of the association of PIK3CA mutations and PTEN loss with efficacy of trastuzumab therapy in metastatic breast cancer. Breast Cancer Res Treat 128: 447-456, 2011.

27. Fountzilas G, Christodoulou C, Bobos M, Kotoula V, Eleftheraki AG, Xanthakis I, Batistatou A, Pentheroudakis G, Xiros N, Papaspirou I, et al: Topoisomerase II alpha gene amplification is a favorable prognostic factor in patients with HER2-positive metastatic breast cancer treated with trastuzumab. J Transl Med 10: 212, 2012.

28. Koumarianou A, Karayannopoulou G, Gourgioti G, Batistatou A, Bobos M, Efstratiou I, Miliaras D, Galani E, Pentheroudakis G, Pectasides D, et al: PAI-1 and HER2 interaction in advanced breast cancer disease: Evidence for added benefit from trastuzumab in HER2-negative patients. Cancer Chemother Pharmacol 75: 1289-1301, 2015.

29. Wolff AC, Hammond ME, Schwartz JN, Hagerty KL, Allred DC, Cote RJ, Dowsett M, Fitzgibbons PL, Hanna WM, Langer A, et al; American Society of Clinical Oncology; College of American Pathologists: American Society of Clinical Oncology/College of American Pathologists guideline recommendations for human epidermal growth factor receptor 2 testing in breast cancer. J Clin Oncol 25: 118-145, 2007.

30. Pavlakis K, Bobos M, Batistatou A, Kotoula V, Eleftheraki AG, Stofas A, Timotheadou E, Pentheroudakis G, Psyrri A, Koutras A, et al: p85 protein expression is associated with poor survival in HER2-positive patients with advanced breast cancer treated with trastuzumab. Pathol Oncol Res 21: 273-282, 2015.

31. Gogas H, Kotoula V, Alexopoulou Z, Christodoulou C, Kostopoulos I, Bobos M, Raptou G, Charalambous E, Tsolaki E, Xanthakis I, et al: MYC copy gain, chromosomal instability and PI3K activation as potential markers of unfavourable outcome in trastuzumab-treated patients with metastatic breast cancer. J Transl Med 14: 136, 2016. 
32. Christodoulou C, Oikonomopoulos G, Koliou GA, Kostopoulos I, Kotoula V, Bobos M, Pentheroudakis G, Lazaridis G, Skondra M, Chrisafi S, et al: Evaluation of the Insulin-like Growth Factor Receptor Pathway in Patients with Advanced Breast Cancer Treated with Trastuzumab. Cancer Genomics Proteomics 15 461-471, 2018

33. Salgado R, Denkert C, Demaria S, Sirtaine N, Klauschen F, Pruneri G, Wienert S, Van den Eynden G, Baehner FL, Penault-Llorca F, et al; International TILs Working Group 2014 The evaluation of tumor-infiltrating lymphocytes (TILs) in breast cancer: Recommendations by an International TILs Working Group 2014. Ann Oncol 26: 259-271, 2015.

34. Sauter G, Lee J, Bartlett JM, Slamon DJ and Press MF: Guidelines for human epidermal growth factor receptor 2 testing: Biologic and methodologic considerations. J Clin Oncol 27: 1323-1333, 2009.

35. Economopoulou P, Kotoula V, Koliou GA, Papadopoulou K, Christodoulou C, Pentheroudakis G, Lazaridis G, Arapantoni-Dadioti P, Koutras A, Bafaloukos D, et al: Prognostic Impact of Src, CDKN1B, and JAK2 Expression in Metastatic Breast Cancer Patients Treated with Trastuzumab. Transl Oncol 12: 739-748, 2019.

36. Perez EA, Suman VJ, Davidson NE, Martino S, Kaufman PA, Lingle WL, Flynn PJ, Ingle JN, Visscher D and Jenkins RB: HER 2 testing by local, central, and reference laboratories in specimens from the North Central Cancer Treatment Group N9831 intergroup adjuvant trial. J Clin Oncol 24: 3032-3038, 2006.

37. Roche PC, Suman VJ, Jenkins RB, Davidson NE, Martino S, Kaufman PA, Addo FK, Murphy B, Ingle JN and Perez EA: Concordance between local and central laboratory HER2 testing in the breast intergroup trial N9831. J Natl Cancer Inst 94: 855-857, 2002.

38. Paik S, Bryant J, Tan-Chiu E, Romond E, Hiller W, Park K, Brown A, Yothers G, Anderson S, Smith R, et al: Real-world performance of HER2 testing - National Surgical Adjuvant Breast and Bowel Project experience. J Natl Cancer Inst 94 852-854, 2002.

39. Kaufman PA, Bloom KJ, Burris H, Gralow JR, Mayer M, Pegram M, Rugo HS, Swain SM, Yardley DA, Chau M, et al: Assessing the discordance rate between local and central HER2 testing in women with locally determined HER2-negative breast cancer. Cancer 120: 2657-2664, 2014.

40. Perez EA, Cortés J, Gonzalez-Angulo AM and Bartlett JM: HER 2 testing: Current status and future directions. Cancer Treat Rev 40: 276-284, 2014

41. Fehrenbacher L, Cecchini RS, Geyer CE Jr, Rastogi P, Costantino JP, Atkins JN, Crown JP, Polikoff J, Boileau JF, Provencher L, et al: NSABP B-47/NRG Oncology Phase III Randomized Trial Comparing Adjuvant Chemotherapy With or Without Trastuzumab in High-Risk Invasive Breast Cancer Negative for HER2 by FISH and With IHC 1+ or 2. J Clin Oncol 38: 444-453, 2020
42. Exman P and Tolaney SM: HER2-positive metastatic breast cancer: A comprehensive review. Clin Adv Hematol Oncol 19: 40-50, 2021.

43. Fiszman GL and Jasnis MA: Molecular Mechanisms of Trastuzumab Resistance in HER2 Overexpressing Breast Cancer. Int J Breast Cancer 2011: 352182, 2011.

44. Sergina NV and Moasser MM: The HER family and cancer: Emerging molecular mechanisms and therapeutic targets. Trends Mol Med 13: 527-534, 2007.

45. Britsch S: The neuregulin-I/ErbB signaling system in development and disease. Adv Anat Embryol Cell Biol 190: 1-65, 2007.

46. Seoane S, Montero JC, Ocaña A and Pandiella A: Breast cancer dissemination promoted by a neuregulin-collagenase 3 signalling node. Oncogene 35: 2756-2765, 2016.

47. Yang L, Li Y, Shen E, Cao F, Li L, Li X, Wang X, Kariminia S, Chang B, Li H, et al: NRG1-dependent activation of HER3 induces primary resistance to trastuzumab in HER2-overexpressing breast cancer cells. Int J Oncol 51: 1553-1562, 2017.

48. Schwarz LJ, Hutchinson KE, Rexer BN, Estrada MV, Gonzalez Ericsson PI, Sanders ME, Dugger TC, Formisano L, Guerrero-Zotano A, Red-Brewer M, et al: An ERBB1-3 Neutralizing Antibody Mixture With High Activity Against Drug-Resistant HER2+ Breast Cancers With ERBB Ligand Overexpression. J Natl Cancer Inst 109: djx065, 2017.

49. Rimawi MF: EGFR Expression in Breast Cancer Association with biologic phenotype and clinical outcomes. Cancer 116: 1234-1242, 2010

50. Ross JS and Fletcher JA: The HER-2/neu Oncogene in Breast Cancer: Prognostic Factor, Predictive Factor, and Target for Therapy. Oncologist 3: 237-252, 1998.

51. Robinson AG, Turbin D, Thomson T, Yorida E, Ellard S, Bajdik C, Huntsman D and Gelmon K: Molecular predictive factors in patients receiving trastuzumab-based chemotherapy for metastatic disease. Clin Breast Cancer 7: 254-261, 2006.

52. Kudlow JE, Cheung CY and Bjorge JD: Epidermal growth factor stimulates the synthesis of its own receptor in a human breast cancer cell line. J Biol Chem 261: 4134-4138, 1986.

53. Cheng $\mathrm{H}$, Ballman $\mathrm{K}$, Vassilakopoulou $\mathrm{M}$, Dueck AC, Reinholz MM, Tenner K, Gralow J, Hudis C, Davidson NE, Fountzilas $\mathrm{G}$, et al: EGFR expression is associated with decreased benefit from trastuzumab in the NCCTG N9831 (Alliance) trial. Br J Cancer 111: 1065-1071, 2014.

54. Ali R and Wendt MK: The paradoxical functions of EGFR during breast cancer progression. Signal Transduct Target Ther 2: 16042, 2017.

55. Wendt MK, Williams WK, PascuzziPE, Balanis NG,SchiemannBJ, Carlin CR and Schiemann WP: The Antitumorigenic Function of EGFR in Metastatic Breast Cancer is Regulated by Expression of Mig6. Neoplasia 17: 124-133, 2015. 